\title{
Psychopathology According to Behaviorism: A Radical Restatement
}

\author{
Marino Pérez-Álvarez \\ University of Oviedo
}

\begin{abstract}
This article is a radical restatement of the predominant psychopathology, which is characterized by nosological systems and by its approach towards a neurobiological conception of the so-called mental disorders. The "radical" sense of this restatement is that of radical behaviorism itself. As readers will recall, "radical" applied to behaviorism means total (not ignoring anything that interests psychology), pragmatic (referring to the practical sense of knowledge), and it also derives from the Latin word for "root" (and thus implies change beginning at a system's roots or getting to the root of things, in this case, of psychological disorders). Based on this, I introduce the Aristotelian distinction of material and form, which, besides being behaviorist avant la lettre, is used here as a critical instrument to unmask the hoax of psychopathology as it is presented. The implications of this restatement are discussed, some of them already prepared for clinical practice.
\end{abstract}

Keywords: Aristotelian causes, radical behaviorism, life's problems, psy-complex, psychological disorders, nosological system

\begin{abstract}
Se hace un replanteamiento radical de la psicopatología dominante, caracterizada por los sistemas nosológicos y por su abocamiento a una concepción neurobiológica de los llamados trastornos mentales. El sentido 'radical' de este replanteamiento no es otro que el propio del conductismo radical. Como se recordará, 'radical' aplicado al conductismo quiere decir total (sin dejar de estudiar nada que interese a la psicología), pragmático (referido al sentido práctico del conocimiento) y de raíz (yendo a la raíz de las cosas, en este caso de los trastornos psicológicos). Sobre esta base, se introduce la distinción aristotélica de materia y forma que, además de ser conductista avant la lettre, sirve aquí de instrumento crítico para desenmascarar el tinglado de la psicopatología según está dado. Se señalan las implicaciones de este replanteamiento, algunas prestas ya para la práctica clínica.

Palabras clave: causas aristotélicas, conductismo radical, problemas de la vida, psycomplex, trastornos psicológicos, sistema nosológico
\end{abstract}

Correspondence concerning this article should be addressed to Marino Pérez-Álvarez, Departamento de Psicología. Universidad de Oviedo. Plaza de Feijoo s/n. 33003- Oviedo (Spain). E-mail: marino@uniovi.es

Translation: Virginia Navascués Howard. 
When I began to develop the proposed title "Psychopathology according to behaviorism," I had two options. According to one, I could take the field of psychopathology in its natural state, apart from theories and clinical procedures, to examine it according to behaviorism. In line with the other option, I could take it as it is, with all its current conceptions and practices, and then disclose how behaviorism sees it, at least a behaviorism especially interested in cultural practices, as will be performed herein.

However, at second glance, I realized that only the second option is possible, that is, there is no option because there is no natural psychopathology, apart from culture, including clinical culture. The clinical culture I refer to is a complex of social conceptions and practices that mediate the entire reality of psychopathology. Therefore, the given reality is a framework or psy-complex that already comprises the "natural state" of psychopathology. What is this framework? We will examine it below but first, let me say a few words about the behaviorism from whence we shall look at this framework.

\section{About Behaviorism}

I refer to Skinner's radical behaviorism. It will not be necessary to highlight radical behaviorism compared to the existing variety of behaviorisms (O'Donohue \& Kitchener, 1999; Pérez-Álvarez, 2004). In fact, the reader can consult in this issue the article by Fuentes (2004), as well as the one by Fuentes and Quiroga (2004). In any case, in this article, I will comment upon three aspects of the meaning of "radical," as applied to behaviorism, which are relevant to this work, simply because it is a radical restatement, in this case, of psychopathology.

First, "radical" has the meaning of "total," referring here to the fact that radical behaviorism studies everything that is part of the field of psychology, including the "subjective experience" and the so-called "inner world," just to mention a few topics that dodge the scientific method. But Skinner's behaviorism does not leave anything out because of method, as does, conversely, methodological behaviorism. In fact, methodological behaviorism, whose most important representative nowadays is cognitive psychology (Moore, 1995), rejects subjective contents because they are not directly observable, readmitting them as hypothetical constructs. These constructs, which are normally presented as supposed cognitive structures and processes, are accessible through behavior, hence, this cognitive psychology is anchored in methodological behaviorism (despite the fact that it does not acknowledge itself under this term).

However, subjective contents are observable, with the peculiarity that they are only observable for one person, the interested party. Therefore, the question is how can a person observe a part of the world that is only there for him or her? The question is, how can people learn to have the "inner world" that they do have and to express their subjective experience, or, vice versa, how does society manage to make this happen? To this respect, Skinner formulated the principles of social learning of the "inner world" and the "subjective experience" in his classic work (Skinner, 1945/1988). Along these lines, the social verbal context of the new acceptance and commitment therapy is a specification of special clinical interest (Hayes, Strosahl, \& Wilson, 1999). Doubtless, the radical behaviorism perspective is privileged to know what I mean when I talk about the inner world, which is crucial in psychopathology.

Second, "radical" also has a "pragmatic" meaning, referring to the practical sense that comprises or should comprise scientific knowledge, in this case, of human behavior. This pragmatism concerns both the destination of knowledge (useful to solve life's practical problems) and its genesis, relative to the essentially practical-operatory character of scientific action rather than to its mental or theoreticist (propositional) character. In this respect, radical behaviorism is opposed to the hypothetical-deductive system, which seems more concerned with inventing constructs than with solving problems. This scientific logic, consisting of inventing constructs, is frequently used in psychopathology, where hypothetical (diagnostic) categories are more abundant than causal (etiological) knowledge (Pérez-Álvarez, 2003; van Praag, 1997).

Third, "radical" still has the etymological sense of "root," referring to the origin of things. Of course, it all depends on where these roots are or, actually, where you look for them because in psychology, wherever you look, you will find (that is how "responsive" an "enthusiastic" search can be). Radical behaviorism seeks the roots of behavior in the environment. With regard to this, environment is specified according to certain conditions called "reinforcement contingencies" and rules or norms that define how the world functions. The relevant point is that the root of behavior is found in certain specifiable environmental conditions, whose specification is performed by means of functional analysis of behavior. Although the usual term is "environment," it would be better to use the word "context," "culture," or even, "world."

The decisive importance of a radical perspective oriented towards the context (the culture, or the world of life), such as that of behaviorism, can be seen in the relation with other alternatives, that are oriented to the individual's inner world (as, to be sure, are most perspectives in psychopathology). The nature of one of these alternatives is neurobiological. Its radical difference from a contextual orientation can be formulated in the following statement: Whereas the neurobiological viewpoint seeks the roots of a disorder in the world of biology, the contextual orientation looks for them in the world of life. Another alternative is of a mental nature, either the mind of psychoanalysis (in the form of a psychic apparatus) or the mind of cognitive psychology (in the form of a processing system). Radical behaviorism does 
not focus on this kind of inner world, because it considers that people are inside the world, not that the world is inside people. In any case, ahead of my world is the world. Therefore, the root of disorders would be found in the world of life, where people's lives are made and undone. And as behavior is what the person does and what makes a person, radical behaviorism's privileged perspective of psychopathology becomes clear.

\section{The Framework of Psychopathology}

Briefly, the framework of psychopathology is characterized by the classificatory systems and the neurobiological conception. The trouble with classificatory systems-represented by the Diagnostic and Statistical Manual of Mental Disorders (DSM hereafter) of the American Psychiatric Association, especially since the 1980 edition; the last edition dating from 2000 (American Psychiatric Association, 1980; 2000)—is that nosological descriptions are not the natural entities they seem to be. Far from being natural kinds, they are practical kinds (Zachar, 2001, 2003). The diagnostic categories as "practical kinds" are useful both for the patients (to have something nameable) and for the clinicians (to endow them with some assumed knowledge).

In fact, classificatory systems serve several other interests, rather than that of supposed scientific knowledge. Among these interests are the legitimization of psychiatry as a medical specialty, billing third-party payers (for example, insurance companies) for health services, and the promotion of drugs (Horwitz, 2002). One could also add the patients' legitimization provided by the illness. Thus, for example, the patients not only accept the notion of illness (diagnosis) with good grace, they even vindicate it (McLean, 1991; Fukuyama, 2002, chap. 3).

Alternatively, the problem of the neurobiological conception is that science is not completely sure about the presumed biological causes of any psychiatric disorder. There are a number of biological factors that may be related in one way or another with various disorders, but that does not make them causes. Instead, they may even be consequences of the disorder. Surely, what characterizes psychiatry is that the diagnostic proliferation is out of phase with etiological knowledge. In fact, the current state of psychiatric diagnosis does not meet the prerequisites of neurobiological research (van Praag, 1997).

The fact that some drugs relieve certain disorders does not prove that the cause of the disorder is the "mechanism" modified by the drug. However, defining a disorder by the effects of a pharmaceutical product has become a psychopharmacological research strategy, known as "listening to drugs," on account of the famous book by Kramen (1993), Listening to Prozac. What this strategy of "listening to drugs" reveals is that, the pharmacological solution, rather than the patient, prevails over the psychological problem. One of the consequences of this strategy is that depression has become epidemic (Pignarre, 2002).

Another troublesome consequence of the neurobiological conception is that it leads to concealing the social causes and psychological solutions of disorders that are actually psychosocial (and not "mental illnesses"). With regard to this, it is noteworthy that there are psychological treatments for every disorder, which are at least as efficient as medication and, at any rate, homogeneous with the psychosocial nature of the disorder (Pérez-Álvarez, Fernández-Hermida, Fernández-Rodríguez, \& AmigoVázquez, 2003). Although it has already been pointed out that people tend to stick to the conception of illness (under the auspices of the pharmaceutical industry), it is also true that many patients/clients search for psychological solutions. In this sense, the people are divided and, perhaps, caught up between the pill and the word, to thus identify, respectively, the psychiatric and psychological "solution."

In view of the above, one could ask in whose hands is psychopathology? The answer is obvious. Psychopathology is in the hands of the designers of the DMS and the manufacturers of drugs. The DMS classificatory system, like a Bible, and the pharmaceutical industry, like a Church, organize the framework of psychopathology. In fact, if this is the way things are, one would have to conclude that psychopathology does not even exist. One cannot expect much from clinical psychology either, to the extent that it has also succumbed to the classificatory systems and is, in any case, a tower of Babel, because of the variety of current schools. Nevertheless, it will still have a critical reconstructive role here (Pérez-Álvarez, 1998).

\section{A Radical Restatement}

With things being the way they are, a radical restatement is necessary. In this instance, radical means total, pragmatic, and root. For the proposed restatement, it is necessary to introduce the pair of terms material/form. These terms are not foreign to the field of psychopathology, although their most frequent version is form/content (Berrios, 1996, p. 20), form understood in the Kantian sense. However, in this work, I shall maintain the original Aristotelian schema of material/form. In fact, I will end up using Aristotle's four causes, that is, the material cause-what are psychological disorders made of? —, the formal cause-what form do they adopt?-, the efficient cause-who makes them that way?-, and the final cause-what end can they have? - (PérezÁlvarez, 2003).

\section{What are Psychological Disorders Made of?}

As could be expected, the material cause points to the material of psychological disorders (psychiatric or mental, 
at this point, it is irrelevant). The question is what are psychological disorders made of? The answer is essential to consolidate psychopathology. It is not the same if disorders are, for example, made of "imbalances in neurotransmitters," "unconscious conflicts," "abnormal experiences," "cognitive dysfunctions," "problematic behaviors," "existential worries," or "pathological communications," to name just a few of the possible answers according to different clinical approaches.

With regard to this study, in the viewpoint of radical behaviorism, the answer would point to life's problems and the behaviors that constitute an attempt to solve them. To begin with, it should be stated that life itself is a problem. On this background are situated many problems, which reach a critical threshold and so, have their own figure. In particular, as will be seen below, there is a special tendency in modern society for the problems that achieve some figure or personal meaning to take on the form of "psychological problems." But the background they come from and the content they are made of are those of life's problems. These life's problems are none other than conflicts, frustrations, disillusions, and changes, all susceptible to analysis in terms of reinforcement contingencies.

Thus, there may be conflict between different reinforcement programs that are incompatible, such as, for example, two systems of life, or the same thing that is simultaneously an immediate positive reinforcer and a long-term negative one. Herein are also included conflicts between norms or cultural rules that govern (and ungovern) people's lives, for example, between dependence and independence, security and freedom, having a personal identity or following the fashion of the day. I refer to contradictory norms, which are probably subjacent to various disorders such as, for example, anorexia and agoraphobia, although current clinical practices ignore their implications. The concerned conflicts would consist of the entire modern 'psychomachia', due to the plurality of options of life itself.

Frustrations are circumstances that prevent one from achieving some possible but often improbable reinforcers. With regard to this, readers are reminded that the consumer society is founded on dis-satisfaction. The various reactions to frustration can become an object of concern, so that they become the center of a person's life, even to the point of draining it. Doubtless, a "frustrated life" can easily provide material for various disorders, in which anxiety and depression may not be lacking.

Disillusions imply the loss of the reinforcing value of something that was maintaining the behavior designed to achieve the reinforcement. This refers to life events that are sufficiently important to become a problem that can turn into a clinical problem. How often has one's life depended on something - a family, a job, a friendship — only to see this source of reinforcers lose its value?

Finally, changes refer here to transitions from one contingency system to another. A contingency system involves practically the entire organization of an individual's life, so that a change can upset and alter the person's whole life. In our society, adolescence and retirement constitute situations that are very characteristic of this type of change. One could add disasters, and these transitions of contemporary society are doubtless somewhat disastrous. It is noteworthy how prone adolescence is to certain disorders such as depression, anorexia and schizophrenia.

Thus, for radical behaviorism, the material of psychological disorders is found in life contingencies. However, as contingencies are always related to people's behavior, and are, in fact, defined by behavior itself, the material of disorders obviously includes behavior. Moreover, the material is behavior, which incorporates the conditions due to the mutual interdependence of behavior-contingency. Indeed, whether or not contingencies as situations or life conditions will constitute a problem will depend on behavior, to the same extent that behavior adapts to the environment and, at the same time, it adapts the environment to behavior itself. Behavior is action, praxis and, in this sense, it is more or less practical or functional to address the contingencies of life.

Behavior, then, is what people do to function in life and, at the same time, it is what makes them persons throughout their lives. Therefore, behavior (continuous action and accumulated deeds) could easily be called drama. Ultimately, "drama" means action and plays, and what could be more of a drama than life itself? Along this line, it would be tempting to use the theater as an image of life. Aside from the notion of drama as action or behavior, the very person is a notion originating in the theater. On the other hand, the notion of the world as a scenario and the norms as scripts is not hard to accept. Psychological disorders would thus reach a relatively new perspective. In this sense, disorders would have a bit of drama, in particular, of more or less dramatic dramas, from tragedies-when life turns into a "catastrophe" (by the way, a term originating in the theater)—-to psychodramas-when life's normal problems are psychologically or psychiatrically dramatized (as is the normalized way in current society). Definitely, the material of psychological disorders is made up of life's dramas, if I may reformulate in these terms the contingencies and behaviors I started out with (Pérez-Álvarez, 2004, chap. 9).

\section{What Form do Psychological Disorders Adopt?}

The question about the form is inseparable from the question about the material. That said, the question would be which form do life's dramas take on, or, you prefer the initial sobriety, what form do life's problems adopt? Briefly, the form would be no other than the known clinical form consisting of the nosological descriptions. This is a clinical form made to the image of the medical model. Moreover, this clinical form is the normal form, scarcely questioned and practically a given fact. 
In order to see the sense of this question, it must be taken into account that every society has its models of "incorrect behavior." It is as though society said, "Don't get this problem but if you do have it, then have it this way" (Linton, 1936/1972, p. 417 of the Spanish edition). In effect, culture offers "model symptoms that, allowing the exteriorization of disorders under standardized forms, makes them more easily controllable" (Devereux, 1970/1972, p. 70 of the Spanish edition).

Well then, the clinical descriptions in accordance with the classificatory systems are the normalized forms that people's problems adopt in modern society. In other words, the clinical descriptions are the ways of psycho-dramatizing life's dramas. As the clinical form is so normalized, it is difficult to conceive of things being any different. What other form could psychological disorders adopt? If one ponders on the limit of the conceivable, one could say the following:

Some "disorders" might not adopt any particular clinical form, so that if they do have a form, it would be because of the tendency to pathologize normal situations. In that case, these situations would not even reach the threshold of problems. Other "disorders" would just be life's normal problems if people assumed that "that's the way life is," a problem unto itself. Other disorders could be assigned to misfortune or life contingency. What has happened is that traditional misfortune has been secularized as a risk and the "risk culture" is ready to ponder on the imponderable, problematizing what would otherwise be just un-fortunate events. On the other hand, problems that "upset" life beyond the former consideration could have religious treatment, as in times that were dominated by the Church, or they could have philosophical treatment, in this case, in accordance with practical philosophies of life.

The reference to "religious treatment" is not exactly meant to vindicate it here, but it can be used as counterbalance when mulling over and thinking about current clinical dominance. In this sense, one would see that the Church has been substituted by the Hospital as the totalizing institutions of life's order and disorders. The health cult would be the new religion. We would be left doubting whether the original sin is stress, trauma, or low self-esteem, but from there on, everyone would need some kind of therapeutic redemption. In fact, redemption is an image that comes from therapy (Orlinsky, 1989). [It is remarkable that the etymology of therapy, from the word therapeúein, "to take care of something," in particular, "to take care of a sick person," originally meant "to take care of Theus," of God.]

With regard to philosophical treatments, in accordance with practical life philosophies, they have a long tradition and currently renewed vigor. Tradition goes back to Hellenistic philosophy. In effect, above all, Hellenistic philosophy consists of practical ethics, which is identified with the medical model. Thus, one of its best accounts, such as probably that of Nussbaum (1994), mentions "Epicurean surgery" for vane desires, or "Skeptic laxatives" for upsetting beliefs, and of "Stoic tonics" for disorderly passions. In fact, well characterized therapies of current psychology such as Ellis' rational emotive therapy and Beck's cognitive therapy have an acknowledged affiliation with Hellenistic ethics. Alternatively, Nussbaum (1994) expounds Hellenistic ethics, assuming their relevance for current world problems. Regarding the current renewed vigor of philosophical therapy, to feel this, suffice it to remember some titles of famous books, such as, for example, More Plato, Less Prozac, The Consolations of Philosophy, Take it with Philosophy, The Philosophical Medicine Kit, About the Good Life, and, finally, the aforementioned Therapy of Desire by Nussbaum.

The above paragraphs indicate that the current clinical model is the standardized form adopted by life's problems in current society. Precisely because of this, they are practical forms, but they are not natural forms produced by "internal dysfunctions" (neurobiological or psychological) like an illness or entities that were foreign to the clinical culture (Zachar, 2001, 2003). According to Horwitz (2002), the "application of this system to the broad range of problems of psychiatric clients was not a triumph of science over ideology, but rather a use of the ideology of science to justify current social practices" (p. 74).

The Aristotelian questions about the material and form of psychological disorders also lead one to ask who makes things this way and, even, if all this does not serve some end. That is, questions about the efficient cause and the final cause.

\section{Who Makes Things This Way?}

Assuming that psychological disorders are not natural forms, it is meaningful to ask who makes them the way they are. Briefly, the answer points to the patients and the clinical practitioners. When all is said and done, it is the patients who have the disorders. However, disorders do not just "crop up" like weeds. Disorders have, or they end up having, a certain form, which, in contemporary society, is usually the standardized clinical form. In this sense, clinicians are also architects of the disorder. In fact, a disorder takes on the form required by the clinician in order to treat it in a practical way, but not its assumed natural form. I do not mean to say that clinicians invent the disorders. Disorders are life's problems that people have. Clinicians help to provide them with the form they wind up adopting (see Brown, 1995).

Now then, patients and the clinicians are part of the same culture and this culture already has a marked clinical character (medicalization and psychologization of society). The very term "patient" assumes this condition. That is why life's problems are so easily reconciled to the consideration of nosological descriptions and, eventually, to "mental 
illness." Although at one time, this psycho-clinical culture had a psychoanalytical profile, nowadays its profile is decidedly medicalizing. Not in vain did an historian of psychiatry (Shorter, 1997) confer the title "From Freud to Fluoxetine" to the last chapter of his book. In short, blaming the brain is the tendency (Valenstein, 1998).

On the other hand, this clinical tendency is currently predominated by the pharmaceutical industry, whose armed right hand consists of the classification systems. In short, one would have to go back to the framework of psychopathology. I only add that the pharmaceutical industry uses the propaganda to propagate faith in psycho-drugs, which involves indoctrination in sickness (when all is said and done, propaganda was invented by the Catholic Church to propagate faith in its creeds). It is no coincidence that "make-believes in psychiatry" (van Praag, 1993) is currently a topic of conversation. This propaganda is aimed directly at the public even more so than at psychiatrists themselves, a new phenomenon. Similarly, the propaganda includes psychiatrists" "continuous training" and research sponsoring, in addition to other influences (Valenstein, 1998, chap. 6). It is therefore hardly surprising that the sponsor of a study is also the loudest predictor of the efficacy of the drug being investigated, as a far-reaching review has shown (Freemantle, Anderon, \& Young, 2000).

\section{What End Can Psychological Disorders Have?}

It would be tempting to say that disorders have the end of addressing the interests of the pharmaceutical industry and, also, of clinicians. However, this is not the issue. The issue is the meaning that disorders may have for the patients themselves. In principle, one could say that disorders are responses to life's problems and, thus, attempts to solve them. One would have to point out that a peculiarity of contemporary society is its low threshold of tolerance and acceptance of disorders, together with its tendency to view life's problems in psychological terms. With regard to this, it is notable that depression has become the most frequent way to cope with life's problems and, thus, it has become epidemic (Pignarre, 2001). In this way, that part of disorders that constitute an attempt to solve problems is lost in favor of medicalization (psychologization), while not discarding that, sometimes, the remedy is worse than the illness, and not forgetting that "therapy" helps the solution process. The so-called evolutionary psychiatry has to do with this.

\section{Implications of such a Radical Restatement}

There are three specific implications of a restatement such as the one presented herein.

1. Unmasking the clinical framework. It has been argued that the diagnostic categories correspond to the supposed neuropsychological entities they claim to be. However, they really correspond to other interests, in particular, to those that have to do with the legitimization of psychiatry as a medical specialty. The neuropsychologizing tendency prevents us from seeing the "social etiology" of disorders and arriving at the corresponding conclusions (see Pilgrim \& Bentall, 1999, for an overwhelming discussion about depression, as Bentall, Jackson, \& Pilgrim, 1998, had previously discussed schizophrenia).

2. Vindicating the critical function of psychology. Psychology and, particularly, a radical restatement (that goes to the root of things) are in a condition to perform a critical function. However, this critique must be total and pragmatic in the above-mentioned sense (see Pérez-Álvarez, FernándezHermida, Fernández-Rodríguez, \& Amigo-Vázquez, 2003, for a discussion of the future task of clinical psychology).

3. Offering alternatives. Aside from the fact that unmasking and critique can offer a new viewpoint of things (which is not unimportant), I propose three ideas, ready for practical application: (a) one idea would be to prepare the patient to abandon the fight against symptoms. In principle, it is paradoxical with regard to clinical logic and common sense, because it breaks the ties with the logic of the medical model. (b) Another idea is to reorient the patient about life. Instead of fighting against symptoms, the patient would be oriented towards valuable goals (values). (c) The third idea would be to promote whatever is required so that patients will assume their corresponding responsibility, in the double sense of being capable of responding with ability to the given circumstances and becoming responsible for their lives. It is noted that these ideas are part of the acceptance and commitment therapy (Hayes, Strosahl, \& Wilson, 1999; Wilson \& Luciano, 2002), precisely, a therapy of Skinnerian roots. No doubt, the capacity for self-improvement that one assumes people to have has been lost when falling into the state of vulnerability fostered by the current "therapeutic culture" (Furedi, 2004). These alternatives are simply ideas that are already established in clinical settings, going back to Alfred Adler, an author vindicated herein (Pérez-Álvarez, 1996, chap. 2).

\section{References}

American Psychiatric Association (1980). Diagnostic and Statistical Manual of Mental Disorders, 3d ed. Washington, DC: American Psychiatric Association

American Psychiatric Association (2000). Diagnostic and Statistical Manual of Mental Disorders (4th ed., revised). Washington, DC: American Psychiatric Association

Bentall, R., Jackson, H.F., \& Pilgrim, D. (1998). Abandoning the concept of "schizophrenia": Some implications of validity argument for psychological research into psychotic phenomena. British Journal of Clinical Psychology, 27, 3003-3024.

Berrios, G.E. (1996). The history of mental symptoms. Descriptive psychopathology since the nineteenth century. Cambridge, UK: Cambridge University Press. 
Brown, Ph. (1995). Naming and framing: The social construction of diagnosis and illness. [Special Issue]. Journal of Health and Social Behavior, 34-52.

Devereux, G. (1970). Essais d'ethnopsychiatrie generale Paris: Gallimard.

Freemantle, N., Anderson, I.M., \& Young, P. (2000). Predictive value of psychopharmacological activity for relative efficacy of antidepressant drugs. Meta-regression analysis. British Journal of Psychiatry, 177, 292-302.

Fuentes, J.B. (this issue). About the purpose of the first centennial of the birth of B. F. Skinner: Philosophical critique of radical behaviorism.

Fuentes, J. B., \& Quiroga, E. (2004). Los dos principios irrenunciables del análisis de la conducta y del conductismo radical. Psicothema, 16, 4, in press.

Fukuyama, F. (2002). Posthuman society. New York: Farrar, Strauss, \& Giroux

Furedi, F. (2004). Therapy culture. Cultivating vulnerability in an uncertain age. London: Rotledge.

Hayes, S.C., Strosahl, K.D., \& Wilson, K.G. (1999). Acceptance and commitment therapy. An experiential approach to behavior change. New York: Guilford.

Horwitz, A.V. (2002). Creating mental illness. Chicago: Chicago University Press.

Kramer, P.D. (1993). Listening to Prozac. New York: Viking.

Linton, R. (1936/1972). Estudio del hombre. México: FCE.

McLean, A. (1990). Contradictions in the social production of clinical knowledge: The case of schizophrenia. Social Science and Medicine, 30, 969-985.

Moore, J. (1995). Some historical and conceptual relations among logical positivism, behaviorism, and cognitive psychology. In J. T. Todd \& E. K. Morris (Eds.), Modern perspectives on B. F. Skinner and contemporary behaviorism (pp. 51-74). New York: Greenwood.

Nussbaum, M. (1994). The therapy of desire. Theory and practice in Hellenistic ethics. Princeton, NJ: Princeton University Press.

O'Donohue, W., \& Kitchener, R. (Eds.) (1999). Handbook of behaviorism. New York: Academic Press.

Orlinsky, D.E. (1989). Researchers' images of psychotherapy: Their origins and influence on research. Clinical Psychology Review, 9, 413-441.

Pérez-Álvarez, M. (1998). La psicología clínica desde el punto de vista contextual. Papeles del Psicólogo, 69, 25-40.
Pérez-Álvarez, M. (1996). Tratamientos psicológicos. Madrid: Universitas.

Pérez-Álvarez, M. (2003). Las cuatro causas de los trastornos psicológicos. Madrid: Universitas.

Pérez-Álvarez, M. (2004). Contingencia y drama. La psicología según el conductismo. Madrid: Minerva.

Pérez-Álvarez, M., Fernández Hermida, J.R., Fernández Rodríguez, C., \& Amigo Vázquez, I. (2003). Camino recorrido y tarea futura de los tratamientos psicológicos. In M. Pérez Álvarez, J.R. Fernández Hermida, C. Fernández Rodríguez, \& I. Amigo Vázquez (Eds.), Guía de tratamientos psicológicos eficaces (vol. 3, pp. 215-236). Madrid: Pirámide.

Pignarre, Ph. (2001). Comment la depression est devenue une epidemie. Paris: La Découverte.

Pilgrim, D., \& Bentall, R. (1999). The medicalization of misery: A critical realist analysis of the concept of depression. Journal of Mental Health, 8, 261-274.

Shorter, E. (1997). A history of psychiatry. New York: Wiley.

Skinner, B. F. (1945/1988). The operational analysis of psychological terms. In A.Ch. Catania \& S. Harnad (Eds.), The selection of behavior. The operant behaviorism of B. F. Skinner: Comments and consequences (pp. 150-164). New York: Cambridge University Press.

Valenstein, E.S. (1998). Blaming the brain. The truth about drugs and mental health. New York: Free Press.

van Praag, H.M. (1993). 'Make-believes' in psychiatry or the perils of progress. (Clinical and Experimental Psychiatry, $n^{\circ} 7$ ). New York: Brunner/Mazel.

van Praag, H.M. (1997). Over the mainstream: Diagnostic requirements for biological psychiatric research. Psychiatry Research, 72, 2001-212.

Wilson, K.G., \& Luciano, M.C. (2002). Terapia de aceptación y compromiso (ACT). Una terapia conductual orientada a valores. Madrid: Pirámide.

Zachar, P. (2001). Psychiatric disorders are not natural kinds. Philosophy, Psychiatry, and Psychology, 7, 167-182.

Zachar, P. (2003). The practical kinds model as a pragmatist theory of classification. Philosophy, Psychiatry, and Psychology, 9, 219-227.

Received June 20, 2004

Revision received July, 23, 2004 Accepted September 1, 2004 